\title{
Giant Occipital Encephalocele
}

\author{
Lt Col Bipin Walia ${ }^{*}$ Brig Pradeep Bhargava ${ }^{+}$, Lt Col (Mrs.) Kavita Sandhu\#
}

MJAFI 2005; $61: 293-294$

Key Words : Encephalocele; Meningocele

\section{Introduction}

E ncephalocele is a broad term representing herniation of cranial contents through a congenital defect in the cranium. If only cerebrospinal fluid (CSF) and meninges herniate, it is termed as a meningocele. A meningoencephalocele is herniation of both neural elements and meninges. The incidence of encephalocele is 1 per 5000 live births [1]. Anterior encephaloceles are more common in males while $70 \%$ of posterior or occipital encephaloceles occur in females. We present one case of a giant occipital encephalocele to highlight the problems encountered in its management.

\section{Case Report}

A 3 day-old female neonate born at term in a peripheral hospital following caesarian section was transferred to a tertiary care teaching hospital. Baby was precious with maternal history of three spontaneous abortions and no live siblings. At birth APGAR score was 10 and weight $4.8 \mathrm{~kg}$. There was a large tense cystic swelling measuring $17 \times 10 \mathrm{~cm}$ arising from posterior part of the head. The inferior part of the swelling ended at the neck (Fig. 1). The two occipital bones could be palpated floating free in the upper part of the swelling. Neonate was active and there was no other discernible congenital anomaly. There was no neurological deficit.

Ultrasonography of the abdomen was normal. Magnetic resonance imaging (MRI) brain showed a giant occipital true meningocele extending from the torcular to the foramen magnum. This was associated with other congenital anomalies including a high tentorium and a Dandy Walker variant with a large posterior cyst communicating with the fourth ventricle. The two cerebellar hemispheres were hypoplastic and pushed anteriorly and laterally against the mastoid (Fig. 2). To prevent spontaneous rupture and to facilitate handling of the neonate, $1000 \mathrm{ml}$ of clear CSF was drained slowly from the encephalocele.

The neonate was intubated with the head supported from below while hanging over the edge of OT table. Then in prone position, extent of scalp resection was marked out to avoid any redundant skin and dead space. Incision was made directly over the sac and dural remnants present in the wall of the sac were dissected free of the overlying skin to create a watertight seal. The high free-floating occipital bones were rotated down and behind the torcula before proceeding with the skin closure.

The immediate post-operative weight of the neonate was $2.2 \mathrm{~kg}$ implying an occipital encephalocele of $2.6 \mathrm{~kg}$. Postoperative period was uneventful and the neonate was discharged on the tenth post-operative day.

\section{Discussion}

Occipital encephaloceles represent approximately 85 percent of lesions seen in the western hemisphere. The occipital encephalocele may occur through a bony defect in the occipital bone or extend into the foramen magnum and involve the posterior arch of atlas. The size of occipital encephaloceles may vary from small to large masses. 15 to 20 percent of children have additional congenital anomalies, including neural tube defects [13]. 60 to $70 \%$ of patients with posterior encephaloceles will develop hydrocephalous requiring ventriculoperitoneal shunting [4]. It may be noted that hydrocephalous, which was not apparent preoperatively can become apparent after the repair of an encephalocele. The neurological prognosis in children depends on the amount of neural tissue that has herniated through the sac. The neural tissue is often dysplastic and gliotic but the presence of microcephaly with a large posterior encephalocele containing significant brain tissue is a predictor of poor neurological outcome [5].

The decision regarding surgery is dependant on various factors including the amount of neural tissue in the sac, other congenital anomalies, etc. The decision must involve the family and other medical personnel. Size alone does not provide an adequate idea of the contents and MRI coupled with magnetic resonance angiography (MRA) is the optimal investigation to visualize the contents of the sac and its relationship to venous sinuses [6,7]. Large encephaloceles with little

"Classified Specialist (Surgery and Neurosurgery), ${ }^{\# C}$ Classified Specialist (Anaesthesiology and Neuroanaesthesiology), Command Hospital (NC), c/o 56 APO, ${ }^{+}$Consultant (Surgery and Reconstructive Surgery), Army Hospital, R\&R, Delhi Cantt.

Received : 18.09.2003; Accepted : 28.02.2004 


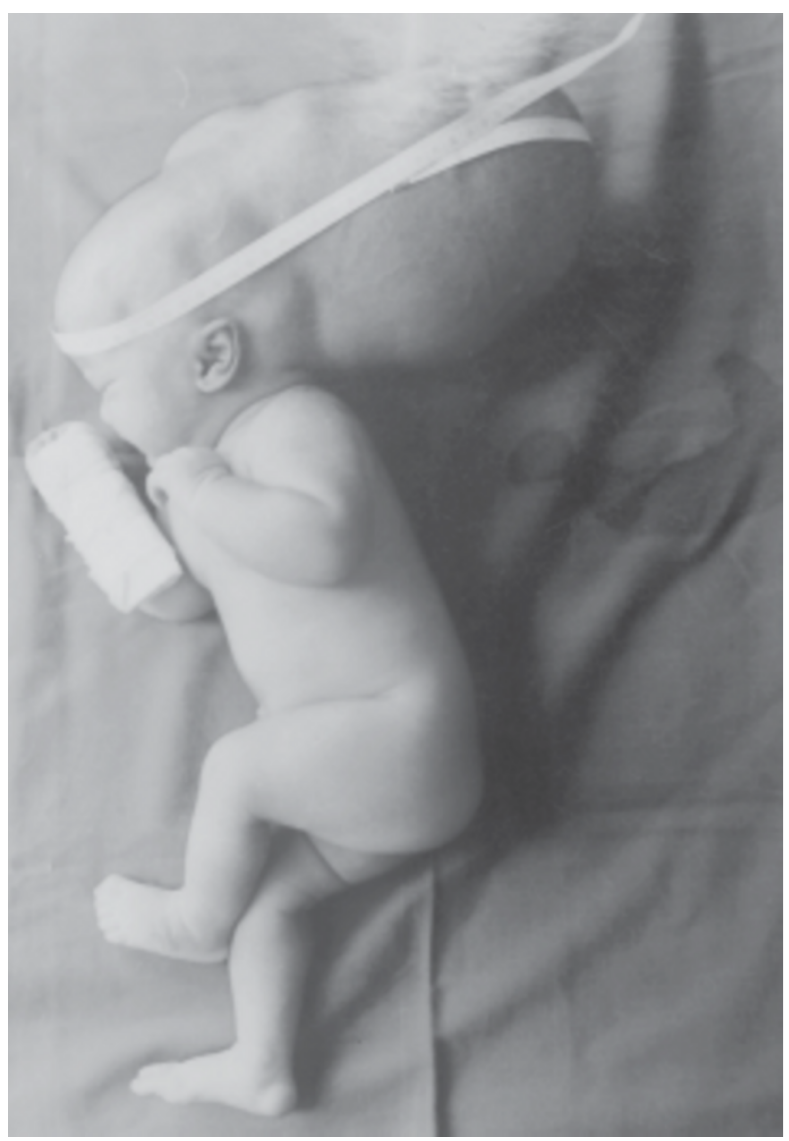

Fig. 1: Photograph showing neonate with giant occipital encephalocele

or no neural tissue have excellent prognosis. Surgical management of these children requires careful attention to pediatric anaesthetic and surgical principles. The removal of a large quantity of CSF causes volume and electrolyte disturbances which need to be corrected perioperatively. Attention has to be given to blood loss, maintenance of body temperature, prone position and its associated complications and careful securing of the endotracheal tube [8,9]. The surgical incision would depend upon the shape, size and location of the lesion. A multi-disciplinary approach with a reconstructive surgeon is always beneficial in case there is inadequate skin for primary closure and skin flap rotation or advancement is required. All gliotic and ischaemic neural contents can be excised taking care of the sinuses that may course through it. Great emphasis is laid on obtaining a two-layered watertight closure. Since the dura is osteogenic, significant amount of bone growth can occur reducing or eliminating the skull defect and caranioplasty is rarely required.

With improvements in radiology, anaesthesia and surgery, the management of occipital encephaloceles needs to be individualised. In our case, with a tense

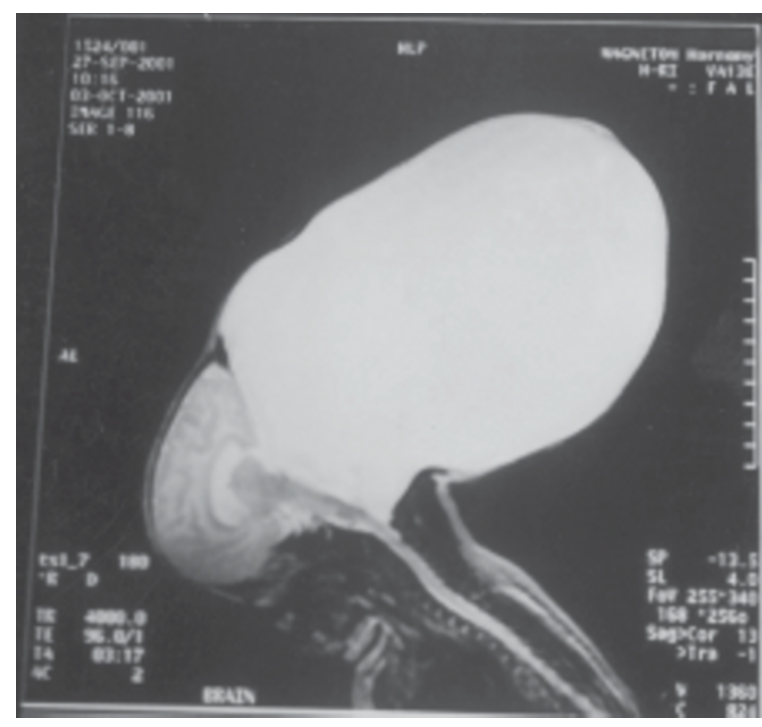

Fig. 2: MRI - T2 saggittal view of head showing giant encephalocele with Dandy-Walker malformation

giant occipital encephalocele problems encountered were essentially because of the large size and induced neonate handling, positioning in the MRI gantry, operation theatre, intubation and blood loss during resection of the large amount of redundant skin. The ultimate prognosis depends on the extent and nature of herniated contents and associated anomalies and many large encephaloceles have an excellent prognosis despite their size.

\section{References}

1. Mealey J Jr, Dzenitis AJ, Hockey AA. The prognosis of encephaloceles. J Neurosurg 1970; 32: 209-18.

2. Bindal AK, Storrs BB, McLone DG. Occipital meningoceles in patients with the Dandy-Walker syndrome. Neurosurgery 1991; 28: 844-77.

3. Simpson DA, David DJ, White J. Cephaloceles: treatment, outcome and antenatal diagnosis. Neurosurgery 1984; 15:1421.

4. Humphreys RP. Encephalocele and dermal sinuses. In: Cheek WR, Martin AE, McLone DG, et al. (editors): Pediatric Neurosurgery: surgery of the developing nervous system, $3^{\text {rd }}$ ed. Philadelphia: Saunders, 1994, 96-103.

5. Lorber J. The prognosis of occipital encephalocele. Dev Med Child Neurol 1967; Suppl 13: 75-86.

6. Chapman PH, Swearingen B, Caviness VS. Subtorcular occipital encephaloceles: anatomic considerations relevant to operative management. J Neurosurg 1989; 71: 375-81.

7. Naidich TP, Altman NR, Braffman BH, et al. Cephaloceles and related malformations. Am J Neuroradiol 1992; 13: 655-90.

8. Creighton RE, Relton JES, Meridy HW. Anaesthesia for occipital encephalocele. Can Anaesth Soc J 1974; 21: 403-6.

9. Newfield P, Hamid RKA. Anaesthesia for paediatric neurosurgery. In: Cottrell JE, Smith DS (editors): Anaesthesia and Neurosurgery. $4^{\text {th }}$ ed., Mosby, 2001: 519-20. 